Boise State University

ScholarWorks

$10-28-2020$

\title{
Developing and Evaluating an Asynchronous Online Library Microcredential: A Case-Study
}

\author{
Rebeca Peacock \\ Boise State University \\ Heather Grevatt \\ Boise State University \\ Ellie Dworak \\ Boise State University \\ Lindsay Marsh \\ Boise State University \\ Shelly Doty \\ Boise State University
}


This is an author-produced, peer-reviewed version of this article. The final, definitive version of this document can be found online at Reference

Services Review, published by Emerald Group Publishing, Ltd. Copyright restrictions may apply. doi: 10.1108/RSR-07-2020-0048

Developing and evaluating an asynchronous online library microcredential: A case-study

\section{Abstract}

Purpose

This paper describes the evolution of an academic library's approach to first-year student information literacy instruction from face-to-face instruction to a fully integrated online microcredential. The design considerations, motivation theory, and evaluation methods used to create and evaluate the course are also discussed, with implications for future library microcredential design, integration, and research in campus first-year seminar courses.

\section{Design/methodology}

In this paper, a multi-method approach is used to evaluate an undergraduate asynchronous online information literacy microcredential embedded in a first-year seminar. Two methods (Likert scale survey and coded reflection essays) were used in order to evaluate whether one method may be more beneficial than the other in future iterations of evaluating microcredentials.

\section{Findings}

In looking at a complex cognitive process such as motivation, multiple approaches to analyzing student thoughts may be beneficial. In addition, the role of the first-year seminar instructor, to help students make a connection to library material, is reinforced as is the need to provide students with accurate expectations for time required to complete online asynchronous microcredential courses. 


\section{Originality}

This paper addresses the evaluation of microcredentials in academic libraries and also has implications for other campus departments investigating the creation of microcourses which are integrated into campus programs. These implications can be addressed in the design and development phases of the microcredential using Keller's ARCS model and in turn, can be improved through iterative evaluation cycles using collected student data.

\section{Keywords}

First-Year Students, Microcredential, ARCS, Motivation, Online Learning, Digital Badges

\section{Introduction}

Technology has radically changed the delivery of higher education (Lemoine and Richardson, 2015). Boise State University is a metropolitan doctoral research granting institution with a student makeup of $73 \%$ White, $13 \%$ Hispanic/Latino, $5 \%$ mixed race, $2 \%$ Black/African American, 2\% Asian, $<1 \%$ American Indian/Alaska Native students. In addition, 1\% of the students are nonresident international students (Boise State University, 2019). The majority of Boise State's undergraduate students (63\%) are Idaho residents and 37\% are out of state students. Additionally, most undergraduates are traditional age college students (Boise State University, 2019) with about $20 \%$ of students representing non-traditional aged students. In fall $2019,14 \%$ of Boise State's total 22,480 students were enrolled in Online Programs. Of the remaining 19,310 students enrolled in a traditionally delivered degree program or who were nondegree seeking, 20\% were enrolled in online classes only (Boise State University, 2019).

As Lemoine and Richardson (2015, p. 37) describe, the trend seen at Boise State University is reflective of a greater push toward digital learning across all higher education, as well as industry and informal learning environments. They suggest that the altered delivery 
This is an author-produced, peer-reviewed version of this article. The final, definitive version of this document can be found online at Reference Services Review, published by Emerald Group Publishing, Ltd. Copyright restrictions may apply. doi: 10.1108/RSR-07-2020-0048

necessitates a comparable shift in the idea of credentialing. This expanded concept of credentials reflects not only on the delivery, but on the very structure and design of the course. Stark and Peacock (2019, p. 1) define microlearning as "skill-based eLearning that is delivered in small chunks, which can be structured in units or individual activities". They go on to explain that when those microlearning situations convey some sort of certificate or badge upon completion, they become microcredentials.

There are a wide range of subtly different definitions for digital badges specifically, with the greatest variation depending on the use of an open or closed system. Biles and Plass (2016, p. 39), summarize badges thusly:

Digital badges are visual indicators of accomplishments or skills within a digital environment that are awarded to the user in recognition of a particular action or series of actions related to the content. These graphic artifacts represent evidence of specific claims about learning recognized via a badge system that identifies the relevant skills and achievements and defines the criteria and assessment guidelines by which the system evaluates whether those criteria have been met.

As Fanfarelli and McDaniel (2019) explain, digital badges can serve multiple purposes. In addition to credentialing, that is, serving to inform an instructor or employer about the skills a recipient possesses, they may act as a form of reward or extrinsic motivation, support goalsetting, or facilitate feedback to the learner. The digital badges comprising the microcredential course under discussion here serve all these purposes to some degree, with the greatest emphasis on credentialing and providing feedback to learners.

The online microcredential at Albertsons Library began as a response to unsustainable growth in library instruction within the university's first-year program, University Foundations 
This is an author-produced, peer-reviewed version of this article. The final, definitive version of this document can be found online at Reference Services Review, published by Emerald Group Publishing, Ltd. Copyright restrictions may apply. doi: 10.1108/RSR-07-2020-0048

(UF) 100 and 200. Beginning in 2012, librarians led in-person instruction sessions. Topics included a variety of information literacy concepts but focused on locating and evaluating scholarly articles. Over time, topics such as advanced search techniques in Google, searching in Google Scholar, and evaluating websites were added to the curriculum. In the Fall 2017 and Spring 2018 semesters, librarians and library staff conducted 183 in-person instruction sessions and liaisons struggled to balance their discipline specific instruction with their required UF classes. This level of instruction was using approximately 7500 Library hours per semester, making it difficult for the library to engage in other campus programs.

Additionally, the instructional format provided little opportunity for authentic formative or summative assessment. There was little way to know, once a librarian had left the classroom, whether students retained any of the conveyed information, as subsequent assignments directly related to the content varied widely between courses. As Moran and Mulvihill (2017, p. 14) describe, "libraries have to be strategic about how they use their time in order to make the biggest impact on students". Beyond the time required for completing the instruction, significant staff time was spent developing and revising curriculum, editing LibGuides, coordinating instruction with the UF faculty, and then subsequently coordinating the library staff scheduled to teach. The high level of staff workload combined with little opportunity to assess learning made one thing clear - this structure was no longer strategically impactful.

In Fall 2018, Albertsons Library addressed this unsustainability by moving first-year experience, information literacy instruction online. At the time of writing, the microcredential at Albertsons Library consists of an Introduction, four badge modules, and a Conclusion. The content is housed in the university Learning Management System (LMS), Blackboard. The course utilizes the platform's "achievement" function to confer the certificate of completion and 
This is an author-produced, peer-reviewed version of this article. The final, definitive version of this document can be found online at Reference Services Review, published by Emerald Group Publishing, Ltd. Copyright restrictions may apply. doi: 10.1108/RSR-07-2020-0048

the adaptive release function to scaffold information literacy concepts. Concepts covered include locating and evaluating information through research databases and Google Scholar, physical and digital library services, and identifying fake news.

Students enrolled in UF 100 and 200 now complete the same microcertification content, however, most students complete the credential in their UF 100 course. Though the microcredential is a required element of the UF curriculum, UF faculty incorporate the badges in different ways. While some provide a significant number of points, others make it comparable to one day of participation. The amount of integration with specific class assignments is also highly variable.

In order to support student motivation, the microcredential originally utilized gamification in the form of a mystery that students were asked to solve, as well as John Keller's ARCS Model for motivational learning design (Keller, 1987a, Keller, 1987b). As discussed further in the conclusion, as a result of the data collected for this study, it was decided that the gamification element was not adding value to the student experience.

This continuous improvement to the microcredential at Albertsons Library reflects a library commitment to best serving our students, however there are limitations to having the course content embedded in first-year experience classes. The process for determining whether transfer students are placed in UF 100 or UF 200 or have the UF 100/200 requirement waived completely is complex (Boise State University, n.d.). This means that many transfer students who have taken a UF comparable course are not receiving information literacy instruction at Boise State even though their waiver-qualifying course may not have included a library or information literacy component. Participating in the first-year experience course also reflects an attempt to appeal to a broad range of skill sets and disciplinary interests, while students may be 
This is an author-produced, peer-reviewed version of this article. The final, definitive version of this document can be found online at Reference Services Review, published by Emerald Group Publishing, Ltd. Copyright restrictions may apply. doi: 10.1108/RSR-07-2020-0048

better served by instruction that speaks specifically to the way information is created, disseminated, and evaluated in their respective fields. These limitations guide our projected goals for the program, which include creating badges specifically for non-traditional, transfer, and graduate students, as well as disciplinary "stretch" badges that scaffold with the existing program while allowing students to achieve greater transfer of learning in their own fields.

\section{Literature Review}

\section{Microcredentials in Higher Education}

In 2014 Bixler asserted that "the entire research base for digital badging is in its infancy" (p. 1). Now in 2020, the research base has grown considerably as the drive toward sustainable instruction and authentic assessment (Raish and Behler, 2019), effective badge design (Rosenberger, 2018), and increased learner autonomy or engagement (Farmer and West, 2016; Ford, et al., 2015) supports a diverse collection of scholarship related to micro-credentialing in higher education. One area of note is the use of micro-credentialing to assist with scalability in information literacy instruction. As libraries strive to provide consistent, scaffolded instruction across multiple courses, badges are one potential solution (Moran and Mulvihill, 2017; LeMire, 2016). An emerging trend in higher education badging research is the use of open badges. Open badges can be exported from the system that created them to be housed or displayed in a different system, allowing a greater level of access and content sharing (Farmer and West, 2016; Grant, 2016). The idea of open badges supports exploration of the way badges are perceived outside of the issuing program or institution (Raish and Rimland, 2016). Ideally, the benefit of open badges is recognition of the learning the badge represents by entities unrelated to the learning, such as employers, professional organizations, or governing bodies (Lemoine and Richardson, 2015). 
This is an author-produced, peer-reviewed version of this article. The final, definitive version of this document can be found online at Reference Services Review, published by Emerald Group Publishing, Ltd. Copyright restrictions may apply. doi: 10.1108/RSR-07-2020-0048

\section{ARCS Model for Motivation}

Keller (2010, p. 7) describes motivation as, “...that which explains people’s desires and choices, as reflected in expectancy-value theory, while volition refers to the actions people take to achieve a goal". Motivation is of particular concern when content is delivered digitally as the online environment can inherently hinder learning (Raish and Behler, 2019). Keller's ARCS Model is a generally accepted way to assess student learning motivation. The ARCS Model addresses four dimensions, Attention, Relevance, Confidence, and Satisfaction, and was the result of a desire both to synthesize human motivation theory into a practicable model and to systematically design for increased motivation in courses (Keller, 1987a, Keller, 1987b).

In Keller's (2010) model, the four dimensions work together to create an overall sense of motivation and can be manipulated by the instructor. Each dimension is defined as follows:

- Attention: The ability the content has to create a sense of interest or simulated curiosity in the learner

- Relevance: The ability the content has to meet learning goals or needs in a positive manner

- Confidence: The ability the content has to help learners feel in control of their learning and the belief that can succeed in learning the content

- Satisfaction: The ability the content has to reinforce the student's effort with a reward (Keller, 2010, p. 45)

Each dimension builds on the previous one to provide a high level of interconnectivity. This means that if one dimension is not meeting overall student motivation needs, the measures for other motivational needs will likely be low, as well. Likewise, if the instruction is improved to meet the needs of one dimension, then the others will likely improve as well (Keller, 1987b; 
This is an author-produced, peer-reviewed version of this article. The final, definitive version of this document can be found online at Reference Services Review, published by Emerald Group Publishing, Ltd. Copyright restrictions may apply. doi: 10.1108/RSR-07-2020-0048

Keller, 2010). In the case of the library's microcredential, the library is responsible for these dimensions in our course. However, the UF faculty are also highly connected to these dimensions in how they relate the material to their class and in how they reward the students' efforts beyond the certificate provided by the library. As Fanfarelli and McDaniel (2019) describe, the UF faculty's influence must be balanced against the intrinsic value of the badge content, or they risk diminishing this value. While some justification of the microcredential's inclusion in the class merits a level of extrinsic motivation, such as points within the class, too great a degree of justification reduces the motivation inherent within a badging model. As Nichols Hess (2015) notes, though the ARCS model is rarely specifically mentioned in information literacy standards, the principles it contains are often reflected in the language used to describe student learning dispositions related to information literacy. This is true of the Association of College and Research Libraries Framework for Information Literacy in Higher Education, which was heavily utilized during the design of the microcourse.

Keller also developed The Instructional Materials Motivation Survey (IMMS). This survey is designed to be used in coordination with the ARCS model when instruction has been self-directed, rather than instructor delivered (Keller, 2010). Like its related tool, the Course Interest Survey (CIS), which is used for instructor-led learning, the IMMS is designed to measure motivation about a specific course instead of the general concept of school (Jokelova, 2013; Keller, 2010). This specificity allows survey questions to be adapted for the course in question, for example changing wording that references a lesson to wording that describes a digital badge. Over time, Keller and other researchers have performed validity testing (on the CIS and then IMMS) and field testing in order to ensure the rigor of the instrument (Jokelova, 2013; Loorback, et al., 2015; Keller, 1984; Naime-Diffenbach, 1991; Small and Gluck, 1994; 
This is an author-produced, peer-reviewed version of this article. The final, definitive version of this document can be found online at Reference Services Review, published by Emerald Group Publishing, Ltd. Copyright restrictions may apply. doi: 10.1108/RSR-07-2020-0048

Wlodkowski, 1999). However, Bixler (2014) highlights the absence of studies assessing motivation in learners completing badges. Abramovich and Wadrip (2016, p. 59) concur, stating, "Our research on badges suggests that the motivational impact of badges is likely connected to learners' identity. However, we have yet to understand just how a badge design can leverage that connection."

\section{Other Motivation Measures.}

Though Keller's work was the primary measure of motivation used for the research presented here, as Reid, et al. (2015) demonstrate there are other measures that may be considered as well. The Badge Opinion Survey was initially developed by Abramovich, Higashi, Hunkele, Schunn, and Shoop, however it was modified for use in Reid et al.'s 2015 study to use language that specifically refers to the badges and English class under review at the time. The survey utilizes a seven-point Likert scale in coordination with 16 questions designed to assess learner motivation related to completion of the badges (p. 396). In their particular study, they also employed three open-ended questions and three phone interview questions to assess student reactions to the badges with greater depth. In a similar manner, Reid et al. built upon the work of McAuley and Tammen's (1989) use of the Intrinsic Motivation Inventory to create a shortened and badge specific version of the assessment. Reid et al. selected 14 questions with a special focus on subscales addressing the Interest/enjoyment dimension, the Perceived competence dimension, the Effort-importance dimension, and the Tension-pressure dimension (p. 395). These questions, in conjunction with a seven-point Likert scale, were administered at three times throughout the badge course, which allowed Reid et al. to make the following observation, "Taken together, these results indicated that learners with high levels of expectancy-value reported higher levels of intrinsic motivation compared to those with lower expectancy-values 
This is an author-produced, peer-reviewed version of this article. The final, definitive version of this document can be found online at Reference Services Review, published by Emerald Group Publishing, Ltd. Copyright restrictions may apply. doi: 10.1108/RSR-07-2020-0048

with regard to earning digital badges, but only at the beginning and end of the semester" (p. 388).

Due to the relatively brief nature of the inventory utilized, it serves as a valuable tool for this sort of longitudinal measure that is not overly onerous for the students involved.

\section{Library Created Online Information Literacy Instruction}

There are a wide variety of examples in the literature of online information literacy instruction, both microcourses and more traditional delivery models, created by academic libraries. This scholarship can be categorized in many ways. For example, the University of Mississippi's utilization of pre- and post-tests incorporated into Blackboard for first-year experience instruction that is otherwise delivered in-person (Dennis, et al., 2011) and the Claremont Colleges Library "Start Your Research Tutorial," a seven-module digital learning object housed in the University LMS (Lowe, et al., 2014), both focus on first-year students' general information literacy needs. Several studies focus on programs created for specific populations even within the first-year experience. Befus and Byrne (2011) demonstrate developing not only a course geared at first-year students, both those in the Federal TRIO program at Wayne State University. Raish and Behler (2019) write about their efforts to support the fully online student community at Pennsylvania State University. Even within a single institution there may be multiple approaches to online instruction. The University of Central Florida Libraries' 15-module information literacy program utilizing object repository Obojobo and the campus LMS is focused on a wide variety of general information literacy concepts including plagiarism (Moran and Mulvihil, 2017). Alternatively, their badge course described in Fanfarelli and McDaniel (2017) is very narrowly focused on preparation for the Adobe Certified Expert certification exam and is only open to students enrolled in the School of Visual Arts and 
This is an author-produced, peer-reviewed version of this article. The final, definitive version of this document can be found online at Reference Services Review, published by Emerald Group Publishing, Ltd. Copyright restrictions may apply. doi: 10.1108/RSR-07-2020-0048

Design. While there are fewer examples of badges used to provide online instruction in academic libraries, Ford, et al. (2015) outline the system created by Portland State University, particularly its inception as the PSU Digital Badges for Creativity and Critical Thinking Project. Stark and Peacock (2019) in their more general overview of microcourses in academic libraries mention the University of Wisconsin-Madison's program as a response to a student desire for asynchronous, self-paced instruction. It is clear that microcourses and digital badges are an expanding trend among many academic libraries.

\section{Method}

\section{Research Context and Sample}

This study examines the attitudes and motivation of undergraduate students enrolled in one of two required first-year seminar courses (University Foundations 100 and 200) with an online information literacy microcredential component. The credential modules were developed by library faculty and administered via the Blackboard LMS. These modules included various quizzes and tests as well as six assignments which were graded by library faculty rather than by

the University Foundations faculty members who instructed the courses. Students received up to $3 \%$ of their total course points for completing the microcredential, as determined by their University Foundations instructor. While the assumption is that students are first or secondsemester undergraduates, in reality the population consists of students from all undergraduate levels and this study did not distinguish between these differences. In this study, ARCS data is gathered to establish a preliminary base that can be used in comparison with future semesters' data, and to analyze the effect of course changes made over time. In addition, the authors examined how various components of the badge program may impact ARCS scores in order to determine future changes. These components include the amount of time required to complete 
This is an author-produced, peer-reviewed version of this article. The final, definitive version of this document can be found online at Reference Services Review, published by Emerald Group Publishing, Ltd. Copyright restrictions may apply. doi: 10.1108/RSR-07-2020-0048

the content and the knowledge the UF instructors display in assigning the badge course. Finally, the course content areas students mention in reflection activities are examined as an indicator of relevance.

\section{Data and Measures}

All students enrolled in the course $(\mathrm{N}=3111)$ were sent the Instructional Materials Motivation Survey (IMMS) Survey, based on Keller's ARCS model to test motivation in course materials (Keller, 2010, p. 282-285), at the conclusion of the Fall 2018 semester. Students received a formal Institutional Review Board (IRB) consent letter via the LMS email system with an anonymous link to a Qualtrics survey. The 393 students who voluntarily responded to this survey became the initial sample for this study. In addition, nine questions were added to the survey. These included seven Likert-style questions to gauge aspects not covered by ARCS such as customer services, UF Faculty course understanding, and perceptions of the narrative storyline. Students were also asked if they were enrolled in the 100 or 200 level of the course and how long it took them to complete the course.

At the end of the Fall semester, after course grades were submitted, a modification was approved by the IRB to collect and review all student quizzes, tests, and assignments in the course. This permitted the use of student final reflections from the course, which included student thoughts on aspects of motivation evaluated by the ARCS assessment. The research team was not permitted to use direct quotations from student reflections so all included quotes are representative, based on student responses, and written by the researchers. A random number generator was used to select 393 student reflections, to match the number of IMMS Surveys completed. 
This is an author-produced, peer-reviewed version of this article. The final, definitive version of this document can be found online at Reference Services Review, published by Emerald Group Publishing, Ltd. Copyright restrictions may apply. doi: 10.1108/RSR-07-2020-0048

The four researchers coded the text of students' reflections, noting areas that related to each of the dimensions defined in the ARCS model, and whether these mentions were positive in nature (e.g. "I could use this information in my history class when I have to write my paper") or negative (e.g. "This wasn't helpful - I learned all of this in my ENG102 class already"). Three rounds of practice coding were required to build consistency amongst the coders. A Fleiss' kappa (Fleiss, et al., 2003) was used to assess interrater reliability, with $\mathrm{k}=0.751$. Once this process was complete, the researchers each coded a subset of the reflection papers. In addition to using ARCS designations, coders assigned designations for 14 different topic areas to gauge student perception of specific course content as an indicator of relevance. This included whether students made general references to usefulness in future classes or for specific courses/assignments and information literacy topics such as using the CRAAP test for evaluating information. Due to limitations of the original IRB protocol we were unable to match IMMS survey results with the individual's final course reflection, and thus could not determine correlation probabilities.

Analysis

The survey data and coding workbooks were reviewed by a fifth researcher who crosstabulated mean ARCS scores with mean results for two of the additional survey questions (time spent completing the microcredential course and perceptions of professors' understanding of the course). Unanswered questions were removed from the dataset at this time. In some cases, reverse coding of questions are indicated by the survey instrument to allow for the negative and affirmative phrasing to better examine the ARCS dimensions; this modification was made to the data (for example replacing a score of 5 with a score of 1). A One-Way Analysis of Variance (ANOVA) was then used to compare means of the ARCS dimensions and the other survey variables. 
Answers to the two additional survey questions were grouped before medians were calculated. Students' perceptions of their professor's understanding of the course were grouped into the following three categories: Very True and Mostly True; Moderately True and Sort of True; Not True. For the analysis of students' estimates of time spent completing the microcredential, data were grouped in the following categories: 0-1 hours, 1-2 hours, $>2$ hours. The results of the student reflections coding were also cleaned. A COUNTIF function was used to calculate the number of positive and negative mentions for each ARCS dimension in the coding sheet. The same process was completed for the topical coding, with the exception that negative mentions were not used for calculations.

\section{Results}

\section{Quantitative Results}

Overall ARCS Scores. Overall ARCS ratings were calculated from the means of all student responses, with a mean $>3.5$ considered high and a mean $<1.5$ considered low. The rating for Confidence was in the high category with a rating of 3.50. The other three measures had intermediate ratings: Attention $=2.80$, Relevance $=3.24$, and Satisfaction $=2.21$. These ratings were based on both UF100 and UF200 students. Therefore, the authors opted to examine if there is a statistically significant difference between the groups.

Difference Between UF 100 and 200 Students. A One-Way ANOVA was conducted to compare ARCS ratings between UF100 and UF200 students. There was a significant difference at the $p<.05$ level for confidence ratings $[F(1,343)=4.04, p=0.031]$. Post hoc tests using the Bonferroni correction revealed that UF200 students reported higher confidence levels (3.61 versus 3.39). However, there was no statistically significant difference between UF100 and UF200 students for the other three ARCS ratings with Attention, Relevance, and Satisfaction 
This is an author-produced, peer-reviewed version of this article. The final, definitive version of this document can be found online at Reference Services Review, published by Emerald Group Publishing, Ltd. Copyright restrictions may apply. doi: 10.1108/RSR-07-2020-0048

having $\mathrm{F}(1,343)=0.010, \mathrm{p}=0.921, \mathrm{~F}(1,341)=0.312, \mathrm{p}=0.577, \mathrm{~F}(1,341)=0.498, \mathrm{p}=0.481$, respectively. Therefore, we can conclude that students in both groups reported similar opinions and students in the 200 level course self-reported higher levels of confidence.

Influence of Professor understanding of the badge course. To investigate whether there is a difference of mean Relevance and Confidence scores and a student's perception of their professors' understanding of the course, the researchers split the sample into students who reported their professors understanding as low, moderate, and high agreement. A One-Way ANOVA was conducted to compare Relevance and Confidence ratings between student reported professor understanding. There was a significant difference $\mathrm{p}<.05$ for confidence ratings showing a statistically significant difference in Relevance and Confidence ratings between these groups $[\mathrm{F}(2,328)=59.060, \mathrm{p}<0.000)$ and $[\mathrm{F}(2,330)=33.161, \mathrm{p}<0.000]$ respectively. Further post hoc analysis revealed:

- Relevance: a statistically significant difference between all reported levels, with means of 2.16, 2.74, and 3.43 respectively. This indicates that professor understanding increases student perceptions of the relevance of the microcredential to their learning.

- Confidence: a statistically significant difference between all reported levels, with means of 3.04, 3.51, and 4.01 respectively. This indicates that professor understanding increases student perceptions of their confidence to complete the microcredential.

Impact of time spent on ARCS ratings. The impact of time spent on student ARCS ratings was investigated by splitting the sample into students who spent under an hour; one to two hours; 
This is an author-produced, peer-reviewed version of this article. The final, definitive version of this document can be found online at Reference Services Review, published by Emerald Group Publishing, Ltd. Copyright restrictions may apply. doi: 10.1108/RSR-07-2020-0048

and over two hours. A One-Way ANOVA was conducted to compare ARCS ratings between the three levels of student reported time:

- Attention: a statistically significant difference was identified at the $\mathrm{p}<.05$ level $[\mathrm{F}(2,341)$ $=3.125, \mathrm{p}=0.045]$. However, post hoc analysis revealed a non-significant difference between groups.

- Relevance: a statistically significant difference was identified at the $\mathrm{p}<.05$ level $[\mathrm{F}(2$, $339)=6.083, p=0.003]$. Post hoc analysis revealed statistically significant differences between group 1 and group 2 but not between group 2 and 3, with means of 2.27, 2.89, and 2.69 respectively.

- Confidence: a statistically significant difference was identified at the $\mathrm{p}<.05$ level $[\mathrm{F}(2$, $341)=14.635, \mathrm{p}<0.000]$. Post hoc analysis revealed statistically significant differences between group 2 and group 3 not between group 1 with means of 3.81, 3.25, and 3.49 respectively.

- Satisfaction: no statistically significant difference was identified at the $\mathrm{p}<.05$ level $[\mathrm{F}(2$, 339) $=2.103, \mathrm{p}=0.124]$

\section{Qualitative Results}

Coding Reflections for Mentions of ARCS dimensions. Four raters coded three rounds of ten student reflections. Our target kappa of greater than 0.75 was achieved after three rounds. The first round yielded $\square=0.024$, the second round $\square=0.530$, and the third round $\square=0.751$. After achieving this goal, the full sample of reflections were coded based on ARCS definitions and course content mentioned. Based on these definitions, most student reflections were coded as either Satisfaction $(72.26 \%)$ or Relevance $(17.81 \%)$. The fraction of negative comments was 
This is an author-produced, peer-reviewed version of this article. The final, definitive version of this document can be found online at Reference Services Review, published by Emerald Group Publishing, Ltd. Copyright restrictions may apply. doi: 10.1108/RSR-07-2020-0048

low, with these two categories receiving the most negative comments, but these accounted for only $3.82 \%$ and $2.04 \%$, respectively (Table 1 ).

$<$ Table 1. $>$

Coding for Topics. Reflections were also coded based on the course content mentioned by students (Table 2). Google Scholar was mentioned the most, being identified in 55\% of the student reflections. Library Database and Library Services were mentioned in about $40 \%$ of the reflections each. Internet Privacy, Fake News, and Other were each mentioned in fewer than $2 \%$ of the reflections.

$<$ Table 2. $>$

\section{Discussion}

This paper reports the results of a semester long study of a microcredential course. The goals of this study were to help a library gather baseline data on student motivation in such a course and examine the viability of different methods of data collection. This study indicates that overall motivation for students in this course needs improvement. In addition, the only area in which UF100 students differed on the IMMS Survey from UF200 was in the Confidence criteria. The ARCS criteria of Attention and Satisfaction were also low compared to Relevance and Confidence and may need further attention. However, because this is a required add-on requirement to their course and at times, not well integrated into their courses, it may be understandable that these ratings were lower. It is important to note that when student end of course reflections were coded, students generally reported language consistent with the ARCS criteria of Relevance or Satisfaction. 
This is an author-produced, peer-reviewed version of this article. The final, definitive version of this document can be found online at Reference Services Review, published by Emerald Group Publishing, Ltd. Copyright restrictions may apply. doi: 10.1108/RSR-07-2020-0048

IMMS Survey Versus Coded Responses

The apparent difference between ARCS ratings gathered via the IMMS Survey versus the coding of reflections requires careful review. Firstly, the researchers note that the samples are very different, with all students completing the reflections (which are a required question in the course) and only a subset completing the voluntary survey. An initial look may indicate that students were more satisfied with the course than IMMS Surveys ratings revealed. However, timeframes present another concern with making direct comparisons between the ARCS ratings in the IMMS survey and the ARCS language coded in the reflections. The reflections were done immediately following the content, while the IMMS survey was not sent to students until December. For most students, who had the course assigned in September and October, they had not thought about the course for at least a month. Therefore, the ARCS ratings may have been impacted by this lag time.

Additionally, the researchers noted that some of the students had difficulty understanding the instructions and did not realize they needed to redo assignments if they received a 0 , until grades were reported to their instructor. This coincided with the release of the survey and some may have used the IMMS survey to quantify their frustration and/or displeasure with the course. Unfortunately, due to the limitations of our IRB we were not able to correlate a student's reflection with their IMMS survey responses.

Another contributing factor may be that reflection questions were not worded in a way to elicit the range of motivational thoughts captured by the IMMS Survey. Instead, the questions were more focused on areas that relate to Relevance and Satisfaction such as how students plan to use course information in the future and the most valuable lessons they learned. However, it is 
This is an author-produced, peer-reviewed version of this article. The final, definitive version of this document can be found online at Reference Services Review, published by Emerald Group Publishing, Ltd. Copyright restrictions may apply. doi: 10.1108/RSR-07-2020-0048

clear at this time that we are unable to indicate that either IMMS Survey or coding student reflections is the better method for gathering this motivation data.

\section{Additional Factors Influencing ARCS Ratings}

The Confidence scores were found to be significantly different between UF100 and 200 students. This is likely due to the fact that UF200 students are generally second year students and may have experience with library instruction in another campus course. However, UF faculty also had a significant impact on student confidence, where we see that the more confident students also reported that their instructors understood the library microcredential. This highlights the importance of continued open communication between the library and UF faculty to ensure that everyone is on the same page.

In addition, there was miscommunication between the library and students on the aspect of the course where students needed to review feedback to assignments and resubmit the assignments. This led to frustration throughout the semester as students who thought they had completed the course were informed that they had not and needed to resubmit assignments. In fact, due to confusion over assignments that were not resubmitted, only $57 \%$ of students received their certificate of completion. This frustration could have impacted student satisfaction responses in the IMMS survey and may not have been reflected in the final reflection assignments.

Student expectations also seem to directly impact all ARCS scores. Although estimated completion times are listed with each module, actual completion times varied considerably between students. It is understandable that some students have prior knowledge that allows them to complete course content more quickly, while novices may need additional time to complete 
This is an author-produced, peer-reviewed version of this article. The final, definitive version of this document can be found online at Reference Services Review, published by Emerald Group Publishing, Ltd. Copyright restrictions may apply. doi: 10.1108/RSR-07-2020-0048

unfamiliar content, making it difficult to provide definitive time estimates. Students who spent time in the range that we estimated generally reported higher ARCS ratings, indicating that expectation management is a key component for motivation. One possible explanation involves student confidence, in that students who felt the content was familiar or too easy, may have sped through the course, impacting motivational factors negatively (Smart and Cappell, 2006). It should be highlighted, as Molteni and Chan (2015, p. 5) note in their comparison of students' self-confidence relative to their information literacy competence, "Being incorrect was independent of one's confidence level." Students who finished quickly, were not necessarily justified in perceiving the course as too easy. Conversely, students who spent more time than estimated may have felt the material was too difficult or required too much time to complete for the reward, decreasing the motivational benefits that the external reward may have added (Deci, 1971). These rewards ranged from participation points to 3 UF course percentage points to a transcript Incomplete. As Reid, et al. (2015) found students who already have a high level of expectancy-value tend to have greater overall motivation related to badge completion. Correlating student IMMS Surveys with specific UF courses was not possible in this study.

Finally, students ARCS ratings for Relevance and Confidence directly correlated with their perception of their instructors' knowledge of the microcredential. Students who felt their faculty have a high understanding of the microcredential also reported higher Relevance ratings. This finding is consistent with good pedagogy - when faculty support the perceived relevance of the assignment, students will in turn find the material more relevant (Keller, 1987b), however in our microcredential this requires a combined effort from library faculty and the students' UF instructor. It also suggests the importance of working with UF faculty to ensure that they are being mindful of how they assign the course, the information they provide students about the 
This is an author-produced, peer-reviewed version of this article. The final, definitive version of this document can be found online at Reference Services Review, published by Emerald Group Publishing, Ltd. Copyright restrictions may apply. doi: 10.1108/RSR-07-2020-0048

assignment, and how it relates to the overall UF course objectives. In addition, students who felt their faculty did not understand the course well indicated a much lower sense of confidence in their ability to complete the course. Conversely, students who felt their instructor knew more about the course had much higher confidence ratings. This impresses upon the library the need to continue our collaborations with the UF instructors in helping them understand the importance of the course and its content, so that they are able to assign the microcredential in a meaningful way for students. In addition, we need to help faculty to create tie-ins to class assignments.

Encouragingly, in many cases, students were able to make the jump between the skills in the microcredential and how they transfer to new situations. The UF faculty are clearly a critical component for student achievement and improving motivation.

\section{Coding reflections}

In coding reflections, we were surprised to note the positive nature of students' statements, given the ARCS ratings from the IMMS survey. In particular, student reflections either encompassed a sense of relevance to their course or other campus courses or a sense of satisfaction, where students reiterated the helpfulness in learning the material but did not connect those feelings to any course or assignment. Indeed, satisfaction was the most commonly coded ARCS criteria. This is in contrast to the results of the IMMS survey, which indicated that satisfaction was the lowest ranking criteria.

Coding reflections also afforded the opportunity to analyze student perceptions of the content in the course by measuring how many times students noted particular content in their reflection. The researchers coded direct mention of content such as "Google Scholar" as well as content that was contained in a larger definition such as "It was helpful to learn about those 
This is an author-produced, peer-reviewed version of this article. The final, definitive version of this document can be found online at Reference Services Review, published by Emerald Group Publishing, Ltd. Copyright restrictions may apply. doi: 10.1108/RSR-07-2020-0048

limiters to help me find articles..." which would be contained in the Advanced Search Strategies content area. We did note that $16.5 \%$ of our coded responses did not contain any mention of any content area. This in itself could be a counter indicator to our data, because it suggests content may not have held relevance for our students. In addition, $38.9 \%$ of our coded responses mentioned that skills could be used in either a specific course or generalized comments about potential future usefulness of the content. These comments indicate a potential for near transfer of learning in that students were actively striving to find connections between the skills they learned in the course and usefulness in other courses. Perkins and Salomon (1992) refer to mindfulness as a condition for transfer of learning and these reflection activities support that as a condition.

\section{Limitations}

This project was primarily initiated to analyze the various assessment techniques available to us in order to make some preliminary changes to the course and decisions about future assessment techniques. Due to this strategy, we were not able to make deeper connections between student grades, reflections, and their IMMS survey. Furthermore, the IMMS survey was delivered months after many students completed the course and because of this, there is concern regarding the accuracy of the results, given that the reflections appeared more positive. This study is also limited by the fact that it considered motivation but did not include an analysis of learning or transfer of learning. While motivation can be a strong component of learning, this is a required activity students must complete for a campus course, in many cases without a solid tiein to course material. Given these circumstances, it might be expected that students report low motivation to the library course material. 
This is an author-produced, peer-reviewed version of this article. The final, definitive version of this document can be found online at Reference Services Review, published by Emerald Group Publishing, Ltd. Copyright restrictions may apply. doi: 10.1108/RSR-07-2020-0048

\section{Conclusion}

Selecting the right assessment techniques for a large-scale instruction project can be a daunting process due to the complexity of teaching and learning. There are many elements of instruction to take into consideration when making the decision and often no one measure can encompass the entire learning experience. In this study we focus on two methods for measuring motivation and analyzing select core elements of the microcredential. This allowed us to make some preliminary changes while re-evaluating our IRB.

One of the first changes we made for future semesters was to reduce the number of assignments we manually graded. We suspect that some of the student frustration with the course was due to confusion about having to redo assignments. Automatically grading more questions provides more immediate feedback to the student. In addition to reducing the number of manually graded assignments, we also incorporated a number of "stop signs" throughout the course to remind students that they would need to check their grades and resubmit assignments if necessary.

For the next school year we are also replacing the mystery theme with a career readiness theme. Here, professionals in our community speak about how their knowledge of how to find and use information in their work is an essential skill. The intention behind restructuring the microcredential to include these interviews is to assist students' transference of concepts by recognizing that information literacy skills are applicable to a wide range of careers.

In addition, we note that it is critical to engage with our UF faculty partners to help them become more familiar with the course and assist them in assigning the course in a meaningful way to their students. Building confidence in the faculty members directly benefits our students by increasing their motivation in the course. Methods such as campus workshops and one-on-one meetings with faculty will be used to further support the UF faculty. 
This is an author-produced, peer-reviewed version of this article. The final, definitive version of this document can be found online at Reference Services Review, published by Emerald Group Publishing, Ltd. Copyright restrictions may apply. doi: 10.1108/RSR-07-2020-0048

We will also submit a modification to our IRB that will allow us to incorporate the IMMS survey into the badge course, allowing us to correlate student performance on quizzes and assignments with their reflection and survey selections. In addition, students will be able to provide their IMMS survey feedback immediately following the completion of the course, rather than waiting until the end of the semester. This will allow us to analyze the data at a deeper level. We will also begin to conduct an item analysis of our quizzes and review methods for measuring transfer of learning within student courses.

Our study shows that while the IMMS survey provided helpful data, the coding of responses provided a deeper level of insight. By using student reflections, the authors were able to measure which content students found most helpful for their future. Moving forward, the authors are unable to recommend one method over the other. Instead, it is recommended that both methods be used in analyzing student motivation in online learning. The students' reflections indicate more than the general feelings of motivation measured in the IMMS survey and begin to get at the issue of transfer of learning. The authors realize that coding of qualitative data can be time consuming, but the rewards in the additional data collected through this method are well worth the time. The authors will work towards overcoming some of the limitations in this preliminary study and seek to connect the dots between motivation, demonstrated learning, and transfer in future projects. 
This is an author-produced, peer-reviewed version of this article. The final, definitive version of this document can be found online at Reference Services Review, published by Emerald Group Publishing, Ltd. Copyright restrictions may apply. doi: 10.1108/RSR-07-2020-0048

\section{Bibliography}

Abramovich, S. \& Wardrip, P. (2016). Impact of badges on motivation to learn. In L.Y.

Muilenburg and Z.L. Berge (Eds.), Digital badges in education: Trends, issues, and cases. (pp. 39-52). New York: Routledge.

Befus, R. \& Byrne, K. (2011). Redesigned with them in mind: Evaluating an online library information literacy tutorial. Urban Library Journal, 17(1), Retrieved from https://academicworks.cuny.edu/ulj/vol17/iss1/2

Biles, M.L. \& Plass, J.L. (2016). Good badges, evil badges? Impact of badge design on learning from games. In L.Y. Muilenburg and Z.L. Berge (Eds.), Digital badges in education: Trends, issues, and cases. (pp. 39-52). New York: Routledge.

Bixler, B. (2014). Digital badges: A conversation on the teaching and learning implications for higher education. Presented at Conference on Higher Education Pedagogy, Blacksburg, Virginia. Retrieved from https://vtechworks.lib.vt.edu/handle/10919/85326

Boise State University. (2019). Student enrollment summary - 10th day fall snapshot. Retrieved from https://www.boisestate.edu/ir/data-and-reporting/university-enrollment-reports/ 
This is an author-produced, peer-reviewed version of this article. The final, definitive version of this document can be found online at Reference Services Review, published by Emerald Group Publishing, Ltd. Copyright restrictions may apply. doi: 10.1108/RSR-07-2020-0048

Boise State University. (n.d.) UF 100/200 placement. Retrieved from

https://www.boisestate.edu/academics-uf/uf-placement/

Deci, E. L. (1971). Effects of externally mediated rewards on intrinsic motivation. Journal of Personality and Social Psychology, 18(1), 105-115. https://doi.org/10.1037/h0030644

Dennis, M.R., Murphey, R.M., \& Rogers, K. (2011). Assessing information literacy comprehension in first-year students. Practical Academic Librarianship.

Fanfarelli, J.R. \& McDaniel, R. (2019). Designing effective digital badges: Applications for learning. New York: Routledge.

Farmer, T. \& West, R.E. (2016). Opportunities and challenges with digital open badges. Educational Technology, 45-48.

Fleiss, J., Levin, B., \& Paik, M. (2003). The measure of interrater agreement. In Statistical methods for rates and proportions (3rd ed., pp. 212-236). Hoboken.: J. Wiley.

Ford, E., Izumi, B., Lottes, J., \& Richardson, D. (2015). Badge it! A collaborative learning outcomes based approach to integrating information literacy badges within disciplinary curriculum. Reference Services Review, 43(1), 31-44. https://doi.org/10.1108/RSR-07-2014-0026 
This is an author-produced, peer-reviewed version of this article. The final, definitive version of this document can be found online at Reference Services Review, published by Emerald Group Publishing, Ltd. Copyright restrictions may apply. doi: 10.1108/RSR-07-2020-0048

Grant, S.L. (2016). History and context of open digital badges. In L.Y. Muilenburg and Z.L.

Berge (Eds.), Digital badges in education: Trends, issues, and cases. (pp. 39-52). New York:

Routledge.

Jokelova, A. (2013, October). ARCS motivational model: Theoretical concepts and its use in online courses. In 2013 IEEE 11th International Conference on Emerging eLearning Technologies and Applications (ICETA) (pp. 189-194). IEEE.

Keller, J. M. (1984). The use of the ARCS model of motivation in teacher training. Aspects of Educational Technology, 17, 140-145.

Keller, J. (1987a). Development and Use of the ARCS Model of Instructional Design. Journal of Instructional Development, 10(3), 2-10. Retrieved from https://www.jstor.org/stable/30221294

Keller, J. M. (1987b). Strategies for stimulating the motivation to learn. Performance+ Instruction, 26(8), 1-7. https://doi.org/10.1002/pfi.4160260802

Keller, J. M. (2010). Motivational design for learning and performance : The arcs model approach. https://ebookcentral.proquest.com

LeMire, S. (2016). Scaling instruction to needs: Updating an online information literacy course. Reference and User Services Quarterly, 56(1), 17-22. Retrieved from http://hdl.handle.net/1969.1/158345 
This is an author-produced, peer-reviewed version of this article. The final, definitive version of this document can be found online at Reference Services Review, published by Emerald Group Publishing, Ltd. Copyright restrictions may apply. doi: 10.1108/RSR-07-2020-0048

Lemoine, P.A. \& Richardson, M.D. (2015). Micro-credentials, nano degrees, and digital badges:

New credentials for global higher education. International Journal of Technology and

Educational Marketing, 5(1), 36-49. https://doi.org/10.4018/ijtem.2015010104

Loorbach, N., Peters, O., Karreman, J., \& Steehouder, M. (2015). Validation of the Instructional Materials Motivation Survey (IMMS) in a self-directed instructional setting aimed at working with technology. British Journal of Educational Technology, 46(1), 204-218.

https://doi.org/10.1111/bjet.12138

Lowe, M.S., Booth, C., Tagge, N., \& Stone, S. (2014) Integrating an information literacy quiz into the learning management system. Communications in Information Literacy.

https://doi.org/10.15760/comminfolit.2014.8.1.156

McAuley, E., \& Tammen, V. V. (1989). The effects of subjective and objective competitive outcomes on intrinsic motivation. Journal of Sport and Exercise Psychology, 11(1), 84-93. https://doi.org/10.1123/jsep.11.1.84

Molteni, V.E. \& Chan, E.K. (2015). Student confidence/overconfidence in the research process. The Journal of Academic Librarianship, 41(1), 2-8.

http://dx.doi.org/10.1016/j.acalib.2014.11.012 
This is an author-produced, peer-reviewed version of this article. The final, definitive version of this document can be found online at Reference Services Review, published by Emerald Group Publishing, Ltd. Copyright restrictions may apply. doi: 10.1108/RSR-07-2020-0048

Moran, C. \& Mulvihill, R. (2017). Finding balance in online library instruction: Sustainable and personal. Journal of Library and Information Services in Distance Learning, 11(1-2), 13-24. https://doi.org/10.1080/1533290X.2016.1223964

Naime-Diffenbach, B. (1991). Validation of attention and confidence as independent components of the ARCS motivational model. [Unpublished doctoral dissertation]. Florida State University.

Nichols Hess, A. K. (2015). Motivational design in information literacy instruction. Communications in Information Literacy, 9(1), 3.

https://doi.org/10.15760/comminfolit.2015.9.1.175

Perkins, D. N., \& Salomon, G. (1992). Transfer of learning. In International encyclopedia of education (pp. 6452-6457). Oxford, England: Pergamon Press.

Raish, V. \& Behler, A. (2019). Library connection: An interactive, personalized orientation for online students. Journal of Library \& Information Services in Distance Learning, 13(1-2), 129149. https://doi.org/10/1080/1533290X.2018.1499247

Raish, V., \& Rimland, E. (2016). Employer perceptions of critical information literacy skills and digital badges. College \& Research Libraries, 77(1), 87-113. https://doi.org/10.5860/crl.77.1.87 
This is an author-produced, peer-reviewed version of this article. The final, definitive version of this document can be found online at Reference Services Review, published by Emerald Group Publishing, Ltd. Copyright restrictions may apply. doi: 10.1108/RSR-07-2020-0048

Reid, A.J., Paster, D. \& Abramovich, S. (2015). Digital badges in undergraduate composition courses: effects on intrinsic motivation. J. Comput. Educ. 2, 377-398.

https://doi.org/10.1007/s40692-015-0042-1

Rosenberger, k. (2018). Designing digital badging programs: Findings from an interview-based study with instructional designers. TechTrends, 63, 477-484. https://doi.org/10.1007/s11528-

$\underline{018-0349-7}$

Small, R. V., \& Gluck, M. (1994). The relationship of motivational conditions to effective instructional attributes: A magnitude scaling approach. Educational Technology, 33-40.

Smart, K. L., \& Cappell, J. J. (2006). Students' perceptions of online learning: A comparative study. Journal of Information Technology Education, 5, 201-219. Retrieved from http://jite.org/docu-ments/Vol5/v5p201-219Smart54.pdf

Stark, A. \& Peacock, R. (2019). Microlearning in academic library instruction. Tips and Trends. ACRL Instruction Section, Fall. Retrieved from http://bit.ly/tipsandrendsfa19

Wlodkowski, R. J. (1999). Enhancing adult motivation to learn: A comprehensive guide for teaching all adults (Rev. ed.). Jossey-Bass. 
This is an author-produced, peer-reviewed version of this article. The final, definitive version of this document can be found online at Reference Services Review, published by Emerald Group Publishing, Ltd. Copyright restrictions may apply. doi: 10.1108/RSR-07-2020-0048

Results of student reflection coding for ARCS dimensions

\begin{tabular}{|c|c|c|c|c|}
\hline & \multicolumn{2}{|c|}{ Positive Mentions } & \multicolumn{2}{|c|}{ Negative Mentions } \\
\hline & $\mathbf{n}$ & $\%$ & $\mathbf{n}$ & $\%$ \\
\hline Attention & 7 & $1.78 \%$ & 1 & $0.25 \%$ \\
\hline Relevance & 70 & $17.81 \%$ & 8 & $2.04 \%$ \\
\hline Confidence & 6 & $1.53 \%$ & 0 & $0.00 \%$ \\
\hline Satisfaction & 284 & $72.26 \%$ & 15 & $3.82 \%$ \\
\hline
\end{tabular}

Table 1. Results of student reflection coding for ARCS dimensions shown as a number of mentions and as a percent of total coded reflections.

Results of student reflection coding for topics

\begin{tabular}{l|rc}
\hline & \multicolumn{2}{c}{ Mentions } \\
\hline Google Scholar & \multicolumn{1}{c}{ n } & \multicolumn{1}{c}{ \% } \\
\hline Library Databases & 157 & $55 \%$ \\
\hline Library Service/Location & 150 & $38 \%$ \\
\hline CRAAP Criteria & 137 & $35 \%$ \\
\hline Applicable to Undefined Class & 100 & $25 \%$ \\
\hline Advanced Search Techniques & 78 & $20 \%$ \\
\hline Peer Review & 65 & $17 \%$ \\
\hline Citations & 58 & $15 \%$ \\
\hline Keywords & 55 & $14 \%$ \\
\hline Applicable to Specific Class & 53 & $13 \%$ \\
\hline Fake News & 6 & $2 \%$ \\
\hline Other & 6 & $2 \%$ \\
\hline Internet Privacy & 3 & $1 \%$ \\
\hline
\end{tabular}

Table 2. Results of student reflection coding for topics shown as a number of mentions and as a percent of total coded reflections. 